\title{
Basophil Band Form Count
}

National Cancer Institute

\section{Source}

National Cancer Institute. Basophil Band Form Count. NCI Thesaurus. Code C130154.

The determination of the number of band basophils in a sample. 